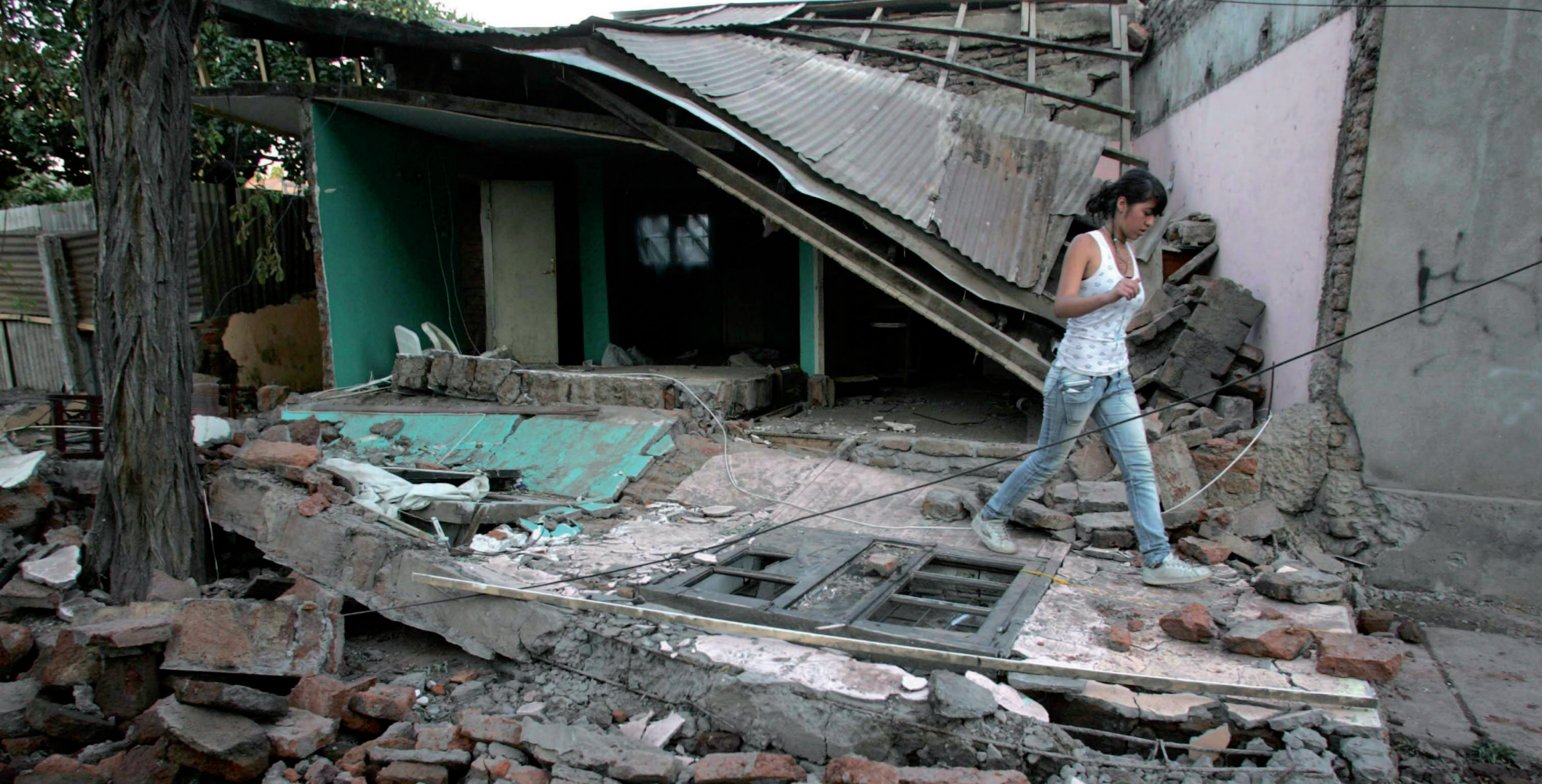

\section{Réplicas en la clase media} precarias rurales (viviendas antiguas de
. sismo. Pero luego se lanzaron otras cifras, en las que se enfatizó que sólo el 6\% de las propiedades tenian este tipo de cobertura endencia de Valores uno puede dilucidar que si el monto asegurado contra incendio sciende a 100, sólo el 42\% de este monto Fueve atender los reclamos no solo de la población de menores recursos, sino también del resto de sectores sociales que ha sufrido considerables pérdidas producto del terremoto. Con respecto a esto creemos que es necesaro hacer algunas consideraciones. Primero, Estado tiene la obligación y la respon- sabilidad de ofrecer algún estándar de viUF1500 podria ascender a \$315.000 (UF mediante la toma de créditos de consumo comprometido con el ofrecimiento de crè-

Sin embargo, más allá del financiamiento, el porcentaje de viviendas con daños es inclusive mayor: $30 \%$.

Sabemos entonces que las pérdidas en inmuebles residenciales son altas, y equivalen a más de seis veces el número de viviendas nuevas disponibles en el pais a diciembre de 2009, y sabemos también que el terremoto adobe), pero también ha afectado a viviendas de mayor valor, departamentos y constá asegurado contra sismo también. vienda a todas las familias sin techo. $Y$ en ofrecer mediaguas para afrontar la llegada del invierno y la época de lluvias. Luego drán transitar hacia una vivienda social definitiva. Segundo, aquellas familias con cobertura de sismo sólo deben hacer frente gastos minimos para activar su seguro. Este gasto es el deducible estándar que este tipo de póliza impone, que en una propiedad de 15). Este gasto fácilmente puede financiarse como se haría para reponer cualquier bien durable. Con un crédito a 36 meses -varios bancos privados y el BancoEstado ya se ha ditos preferenciales de reconstrucción- el pago mensual (al $0.5 \%$ nominal) apenas scendería a $\$ 9.600$. la ciudadania espera que el Estado vele por cumplimiento de las garantias (de construcción) y brinde asesoramiento a las familias afectadas, tal como lo han estado haciendo muchas municipalidades. En este sentido, es necesario investigar también si la aparente raglidad de algunos edificios nuevos esta prácticas de construcción. La clase media practicas de construction. La clase media que, cuando fuera pertinente, se castigue funcionarios o privados irresponsables.

\section{Cuánto cuesta el terremoto}

La política fiscal debe seguir siendo expansiva, tanto como lo fue el año pasado debido a la crisis mundial. Carlos Garcia*

"Ph.D. en Economía, UCLA. Profesor Facultad de Economia y Negocios UAH

Sin rodeos, se puede afirmar que el tenimoperado del PIB para el 2010, y que sus efectos pueden extenderse hasta más de dos años. Estos cálculos son obtenidos utilizando un modelo macroeconómico estándar que permite medir los efectos diferentes shocks sobre la economía.

$\begin{aligned} \text { Para los legos, estos modelos son como } & \\ \text { los sismó } & \end{aligned}$ los sismografos que los economistas han desarrollado. Un shock es definido como nómico.

Conceptualmente, los efectos de un terremoto son asimilables a un shock negativo muy persistente que afecta dicapacidad de producción de áreas claves de la economía. Hay que considerar, además, el esfuerzo de reconstruceion. Uno de los efectos inmediatos es pue resura mucho más dificil y oneroso te en aquellas zonas más golpeadas por t sismo. . Las consecuencias son numeespeculación por las presiones de costos la inflación se puede incrementar por lo menos en un 3\% por sobre las proyecciones esperadas para el año 2010. Segundo, el capital se vuelve menos rentable, con lo cual cae la inversión, afectando la capacidad productiva del país por años. Tercero, las expectativas de una menor demanda
impactan negativamente en el empleo, los salarios y el consumo de muchos chilenos. Desde un punto de vista de la política enfrentar la mayor inflación puede se ambién inminente $\mathrm{Si}$ el mandato de Banco Central de defender la estabilidad puede subir hasta en 300 puntos base Ciertamente seria un error: al terremoto geológico, seguido del social que todos el sector financiero debilo a que el aumento de tasas restinge el cirulante y asi

Sn tiempos de emergencia. La política fiscal ebe seguir siendo expansiva, tanto com o fue el año pasado debido a la crisis munial. Y no debemos permitir que el peso aprecie excesivamente, ya que las réplica seguiran en el sector exportador. Los chileteúricas de cada dia, como para seguir Chile se levantará y superará este amarco momento, pero será más rápido si las politicas macro son las correctas. Debemos seguir estimulando la economía durante no solo para compensar los efectos directos del terremoto, sino también par as aciguadas las expectativas de torno razonable a un crecimiento normal de la economía. conocemos, tendriamos una fuerte replica nos ya tenemos demasiado con las replicas 